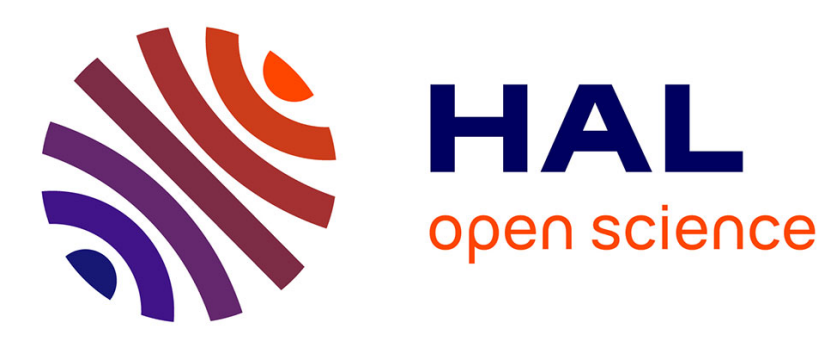

\title{
Structural build-up of rigid fiber reinforced cement-based materials
}

Arnaud Perrot, Thibaut Lecompte, Patrice Estellé, Sofiane Amziane

\section{To cite this version:}

Arnaud Perrot, Thibaut Lecompte, Patrice Estellé, Sofiane Amziane. Structural build-up of rigid fiber reinforced cement-based materials. Materials and structures, 2013, 46 (9), pp.1561-1568. 10.1617/s11527-012-9997-9 . hal-00770565

\section{HAL Id: hal-00770565 https://hal.science/hal-00770565}

Submitted on 1 Feb 2013

HAL is a multi-disciplinary open access archive for the deposit and dissemination of scientific research documents, whether they are published or not. The documents may come from teaching and research institutions in France or abroad, or from public or private research centers.
L'archive ouverte pluridisciplinaire HAL, est destinée au dépôt et à la diffusion de documents scientifiques de niveau recherche, publiés ou non, émanant des établissements d'enseignement et de recherche français ou étrangers, des laboratoires publics ou privés. 
1 STRUCTURAL BUILD-UP OF RIGID FIBER REINFORCED CEMENT-BASED

\section{MATERIALS}

3

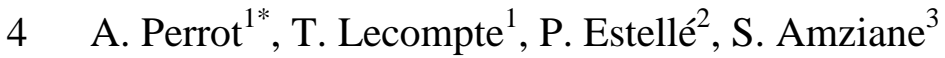

5 (1) Laboratoire d'ingénierie des Matériaux de Bretagne, Université de Bretagne Sud, Université Européenne de

6 Bretagne - Centre de Recherche Christiaan Huygens, BP 92116, 56321 LORIENT Cedex, France

7 (2) Laboratoire de Génie Civil et de Génie Mécanique, Université de Rennes 1, Université Européenne de

8 Bretagne, 3, rue du clos Courtel, BP 90422, 35704 Renne Cedex, France

9 (3) Clermont Université, Université Blaise Pascal, EA 3867, Laboratoire de Mécanique et Ingénieries, BP

10 10448, F-63000 Clermont-Ferrand, France

11

12

*: Corresponding author

13

Arnaud Perrot, Mail: arnaud.perrot@ univ-ubs.fr ; Tel: +33 2 97874577; Fax: +33 297874576

14

Abstract:

The structural build-up of rigid fiber reinforced cement-based materials is studied. It has recently been shown that the behaviour of fiber reinforced concrete depends on the orientation of the fibers that has to be optimized during casting. As a result, there is a great interest to study the rheology of fiber reinforced concrete. One of the most important characteristic of modern fresh concretes is the structural build-up which is involved in many recent issues of concrete casting. This characteristic depends on the cement pastes chemical activity. This present work shows that structural build-up modelling used for common concretes can be generalized to fiber reinforced concretes. It can be shown that, if the inclusions percolation threshold is not reached, the structural build-up rate $\mathrm{A}_{\text {thix }}$ is amplified by the addition of fibers and aggregates. Finally, this amplification of the structuration is estimated using modelling initially developed for spherical inclusions and aggregates. 


\section{Introduction}

(2)

Reinforcing concrete with steel fibers improves the mechanical behaviour of the concrete in different ways. It explains why steel fibers reinforced concrete has been the subject of numerous studies in the past recent years (Altun et al. 2007; Ferrara et al. 2007; di Prisco et al. 2009; Rokugo et al. 2009; Tokgoz 2009; Walraven 2009; Wang et al. 2010; Kovler and Roussel 2011). Steel fibers are known to improve the ductility, the tensile behaviour and the resistance to cracking of concrete (Wille et al. 2012; Ferrara et al. 2007; Pujadas et al. 2012; Colombo et al. 2010; Ferrara et al. 2011). It has also been showed that steel fibers increase the flexural strength and hence that steel fibers can be seen as a partial or total alternative to common steel rebars (Katzer and Domski 2012; Michels et al. 2012).

Many researchers have pointed out that the efficiency of the steel fibers reinforcement depends on their dispersion and orientation (Boulekbache et al. 2010; Kang and Kim 2011; Boulekbache et al. 2012). As example, tensile and shear strengths are largely influenced by the fibers orientation.

Consequently, recent researches have focused on the monitoring of the fibers orientation in order to optimize the aimed mechanical behaviour using two main techniques. The first one consists in using magnetic fields to monitor the fibers orientation (Ferrara et al. 2012a; Ferrara et al. 2012b; Torrents et al. 2012). The second one consists in a flow-induced orientation of the fibers (Boulekbache et al. 2010; Martinie and Roussel 2011; Boulekbache et al. 2012). For the second technique, the material rheological behaviour description is required in order to predict the fibers orientation (Martinie et al. 2010; Martinie and Roussel 2011; Laranjeira et al. 2012; Laranjeira et al. 2011).

Rheology of steel fibers reinforced concrete has already been studied by many researchers (Kaufmann et al. 2006; Kuder et al. 2007; Wallevik 2009; Martinie et al. 2010; Martinie and 
Roussel 2011). Martinie et al. (2010) provides a classification of the fiber stiffness according to the concrete yield stress. They also shows that steel fibers can be considered as rigid if the deformation of the fibers due to shearing remains negligible in front of the fiber length. For such rigid fibers, the authors show that the concrete yield stress depends on a relative packing which depends on the aggregate volume fraction, fiber aspect ratio $\mathrm{r}$ (ratio of the fiber length $l_{f}$ over the fiber diameter $d_{f}$ ) and fiber volume fraction. Such approach provides a simple and efficient tool that can be very helpful for mix-design.

However those studies do not focus on the time-dependent behaviour of the concrete (Lapasin et al. 1979; Roussel 2005, 2006; Wallevik 2009). Lapasin et al. have shown that the cementbased pastes are thixotropic (Lapasin et al. 1979). Roussel and co-workers have shown that rheological behaviour of the cement paste at rest exhibits a structural build-up that leads to a linear increase of the yield stress (Roussel 2005, 2006). This behaviour is due to reversible grains nucleation by CSH formation at the grains contact points (Roussel et al. 2012). The structural build-up rate denoted $\mathrm{A}_{\text {thix }}$ and expressed in Pa.min ${ }^{-1}$ is the rate of the yield stress increase of a cement-based material left at rest. It can be easily computed as the slope of the yield stress vs. resting time curve at very early age (few dozens of minutes). This coefficient has been showed to be sufficient to describe casting process issues such as formwork pressure (Ovarlez and Roussel 2006; Tchamba et al. 2008; Perrot et al. 2009) or distinct layer casting (Roussel 2007; Roussel and Cussigh 2008).

This study aims to describe the structural build-up behaviour of rigid fiber reinforced cementbased materials. This will help to predict the time of casting and transportation available for fiber reinforced concrete. This present work shows that structural build-up modelling used for common concretes can be generalized to fiber reinforced concretes. Indeed, it is highlighted that the evolution of the yield stress of fiber reinforced concrete at rest is linear and that the structuration rate $\mathrm{A}_{\text {thix }}$ can be used. For this study, an experimental campaign has been 
performed. The yield stress of six different mortars has been measured at five different resting times (from 0 to 40 minutes of rest). For each mortar, different fiber volume fractions are added. It can be shown that, if the inclusions percolation threshold is not reached, the structural build-up rate $A_{\text {thix }}$ is amplified by the addition of fibers and aggregates. Especially, the influence of relative packing as described by Martinie et al. (Martinie et al. 2010) on the structural build-up coefficient is analysed. A biphasic approach is considered with no physicochemical interactions between the particles ad the paste. It is assumed that inclusions do not absorb water, in spite of the fiber high surface exchange. Finally it is shown that the modelling initially developed for spherical inclusions and aggregates (Mahaut et al. 2008b) in order to predict the structural build-up rate are also valid with fibers.

\section{Materials and methods}

\subsection{Materials}

A CEM I type cement of specific gravity 3.15 is used in this study. Its specific surface measured using a Blaine apparatus is $3390 \mathrm{~cm}^{2} / \mathrm{g}$.

The sand is a usual Loire river-sand. It has minimum /maximum sizes of $20 \mu \mathrm{m}$ to $3.15 \mathrm{~mm}$ and an absorption capacity of $0.9 \%$.

High range water reducing admixture (HRWRA) is also used. It is a polycarboxylate type polymer conditioned in liquid form containing $20 \%$ of dry material. Its recommended dosage ranges from 0.3 to $3 \%$ per weight of cement. In this study, two dosages of $1.5 \%$ or $2.5 \%$ in mass of cement were chosen depending of the studied mortar. The HRWRA is added to the mixing water before water/cement contact. 
101 Tested fibers are short steel fibers. Their specific gravity is 7.85 and their young modulus E is

$102210 \mathrm{GPa}$. They have a length of $6 \mathrm{~mm}$ and a diameter of $160 \mu \mathrm{m}$ leading to an aspect ratio $\mathrm{r}$ of

$103 \quad 37.5$.

104 According to the criterion defined by Martinie et al., the ratio of the deflexion $\mathrm{f}$ over the fiber

105 length $l_{\mathrm{f}}$ when the fiber is sunk into a cement-based paste exhibiting a yield stress denoted $\mathrm{t}_{0}$

106 is:

$107 \quad \frac{\mathrm{f}}{1_{\mathrm{f}}}=\frac{\tau_{0} \mathrm{r}^{3}}{\mathrm{E}}$

108 For the present fibers, this ratio ranges from $0.012 \%$ to $0.12 \%$ for a paste yield stress between

$109100 \mathrm{~Pa}$, and $1 \mathrm{kPa}$. This clearly shows that this type of fiber can be considered as rigid even

110 with firm ordinary concrete (exhibiting a yield stress of the order of $1 \mathrm{kPa}$ ).

111 The different mix designs are presented in table 1. Tested fiber volume fraction ranges from 0

112 to $6 \%$, and the sand volume fraction ranges from 0 to $36 \%$. Reference cement pastes, with no

113 aggregate are also tested. Two W/C ratios were tested, with different HRWRA dosage to

114 evaluate the influence of the initial yielding behaviour of the samples on their setting at rest.

115 A total of 29 mixes are tested.

116 Water and HRWRA are mixed with dry powder and fibers in a planetary Hobart mixer. The

117 mixing phase consists in two steps: 2 minutes at $140 \mathrm{rpm}$ and then 3 minutes at $280 \mathrm{rpm}$. 


\begin{tabular}{|c|c|c|c|c|c|c|}
\hline $\mathrm{N}^{\circ}$ & Name & $\mathrm{W} / \mathrm{C}$ & $\mathrm{Pl} / \mathrm{C}$ & $S / C$ & $\phi_{\mathrm{f}}(\%)$ & $\phi_{\mathrm{s}}(\%)$ \\
\hline 1 & \multirow{4}{*}{$\mathrm{CP} 1$} & \multirow{22}{*}{0.34} & \multirow{22}{*}{0.015} & \multirow{4}{*}{0} & 0 & 0 \\
\hline 2 & & & & & 0.05 & 0 \\
\hline 3 & & & & & 1 & 0 \\
\hline 4 & & & & & 2 & 0 \\
\hline 5 & \multirow{6}{*}{$\begin{array}{c}\text { CP 1+ } \\
0.14 S\end{array}$} & & & \multirow{6}{*}{0.3} & 0 & 14 \\
\hline 6 & & & & & 0.5 & 14 \\
\hline 7 & & & & & 1 & 14 \\
\hline 8 & & & & & 2 & 14 \\
\hline 9 & & & & & 5 & 14 \\
\hline 10 & & & & & 6 & 14 \\
\hline 11 & \multirow{6}{*}{$\begin{array}{c}\text { CP 1+ } \\
0.35 S\end{array}$} & & & \multirow{6}{*}{1} & 0 & 36 \\
\hline 12 & & & & & 0.5 & 36 \\
\hline 13 & & & & & 1 & 36 \\
\hline 14 & & & & & 1.5 & 35 \\
\hline 15 & & & & & 2 & 35 \\
\hline 16 & & & & & 3 & 35 \\
\hline 17 & \multirow{6}{*}{$\begin{array}{c}\text { CP } 1+ \\
0.28 S\end{array}$} & & & \multirow{6}{*}{0.7} & 0 & 28 \\
\hline 18 & & & & & 0.5 & 28 \\
\hline 19 & & & & & 1 & 28 \\
\hline 20 & & & & & 1.5 & 28 \\
\hline 21 & & & & & 2 & 27 \\
\hline 22 & & & & & 4 & 27 \\
\hline 23 & \multirow{3}{*}{ CP 2} & \multirow{10}{*}{0.29} & \multirow{10}{*}{0.025} & \multirow{3}{*}{0} & 0 & 0 \\
\hline 24 & & & & & 1 & 0 \\
\hline 25 & & & & & 2 & 0 \\
\hline 26 & \multirow{4}{*}{$\begin{array}{c}\text { CP } 2+ \\
0.14 S\end{array}$} & & & \multirow{4}{*}{0.3} & 0 & 14 \\
\hline 27 & & & & & 1 & 14 \\
\hline 28 & & & & & 2 & 14 \\
\hline 29 & & & & & 3 & 14 \\
\hline 30 & \multirow{3}{*}{$\begin{array}{c}\text { CP 2 + } \\
0.42 S\end{array}$} & & & \multirow{3}{*}{1.2} & 0 & 42 \\
\hline 31 & & & & & 1 & 42 \\
\hline 32 & & & & & 2 & 42 \\
\hline
\end{tabular}

Table 1: Summary of tested mixtures (W/C: water over cement mass ratio, HRWRA/C:

128 HRWRA over cement mass ratio, S/C: sand over cement mass ratio)

\subsection{Structural build-up measurements}

131 Different techniques can be used to measure the structural build-up coefficient $\mathrm{A}_{\text {thix }}$ (Roussel

132 2006; Amziane et al. 2008; Mahaut et al. 2008b; Sleiman et al. 2010; Khayat et al. 2012;

133 Lecompte et al. 2012). Field oriented test methods such as portable vane test, plate test or

134 undisturbed slump flow allow accurate measurements of the structural build up of resting 
cement-based pastes. In this study, vane test on undisturbed samples is used. This method is

136 accurate and relatively easy to carry out (Mahaut et al. 2008b; Lecompte et al. 2012).

137 An Anton Paar Rheolab QC rheometer equipped with a vane geometry well adapted for

138 cement paste and mortar is used. The vane geometry used in this study consisted of four

139 blades around a cylindrical shaft. The vane height and diameter are respectively $60 \mathrm{~mm}$ and

$14040 \mathrm{~mm}$. These dimensions allow for an accurate measurement of the yield stress from 10 to

$141700 \mathrm{~Pa}$. The ratio between fiber length and tool diameter is close to seven and ensures that the

142 measurement provides a value representative of the paste behaviour.

143 Yield stress is the more relevant parameter to study the impact of rheology on common

144 casting process. However its measurement is especially difficult to achieve as the yield stress

145 largely depends on the structuration state of the nucleating cement suspension (Roussel et al.

146 2012). As a result, yield stress of cement based materials increases at rest as the material

147 structurates. Roussel predicts a linear increase of the yield stress $\tau_{0}$ with resting time (Roussel

$148 \quad 2005,2006):$

$149 \tau_{0}=\tau_{0}{ }^{\mathrm{i}}+\mathrm{A}_{\text {thix }} \cdot \mathrm{t}_{\text {rest }}$

150 where $\mathrm{t}_{\text {rest }}$ is the resting time in minutes, $\tau_{0}{ }^{i}$ is the yield stress just after mixing, in $\mathrm{Pa}$, and

$151 A_{\text {thix }}$ is the structural build up rate, in $\mathrm{Pa} /$ minute. As a result, the resting time of the material

152 must always be considered when measuring its yield stress.

153 After mixing, the fiber dispersion and isotropic orientation was checked. Then, the material

154 was slowly poured in five different cylindrical containers of $10 \mathrm{~cm}$ in diameter and $15 \mathrm{~cm}$ in

155 height. The slow pouring velocity is required in order to avoid the fiber orientation. The

156 containers walls were covered with sandpaper to avoid material slippage during tests. The

157 first vane test is then performed, few seconds after the end of the pouring step and close to

158 one minute after the end of the mixing step. We consider that the first vane test starts the

159 resting period. Also, it can be noted here that a pre-shear phase before each test could not be 
160 performed for this specific study as it would have strongly modified the orientation of the

161 fibers in the bowl and the structuration state of the cement paste.

162 A measurement stage was performed during $180 \mathrm{~s}$ on the Anton Paar rheometer to obtain the 163 yield stress at five given resting times, following the procedure described by Mahaut et al.

164 (Mahaut et al. 2008b). Stress growth is used to determine the yield stress with an apparent 165 shear rate of $0.001 \mathrm{~s}^{-1}$. At such shear rate, viscosity effects are negligible. As a consequence, 166 the yield stress is computed from the maximum torque value which is required for the onset of 167 the flow, i.e. when the apparent yield stress (static yield stress) is reached on the cylindrical 168 shearing surface:

$$
\tau_{0}=\frac{C}{\frac{\pi \cdot D^{2}}{2} \cdot\left(H+\frac{D}{3}\right)}
$$

170 where $\mathrm{C}$ is the torque peak value, $\mathrm{H}$ and $\mathrm{D}$ are respectively the tool height and diameter.

171 This value depends on the structuration state of the cement-based materials and is different 172 than the dynamic yield stress (intrinsic yield stress) (Roussel 2005). If the material is 173 unstructured (i.e. with no resting time), the torque vs. time curve does not exhibit a peak but a 174 plateau and the dynamic yield stress is measured.

175 Then as shown on figure 1, the torque vs. time curve may present different trends depending 176 on the resting time and the fiber content. With no resting time and no fiber, the curve presents 177 a torque plateau (this is also the case with low amount of fibers). After a resting period or for 178 high fiber content, a peak curve is obtained. This is due to the cement paste destructuration 179 after a resting period and to the energy required for the fiber orientation for mix with high 180 amount of fibers (Martinie et al. 2010).

181 Every ten minutes, an undisturbed sample was measured. 


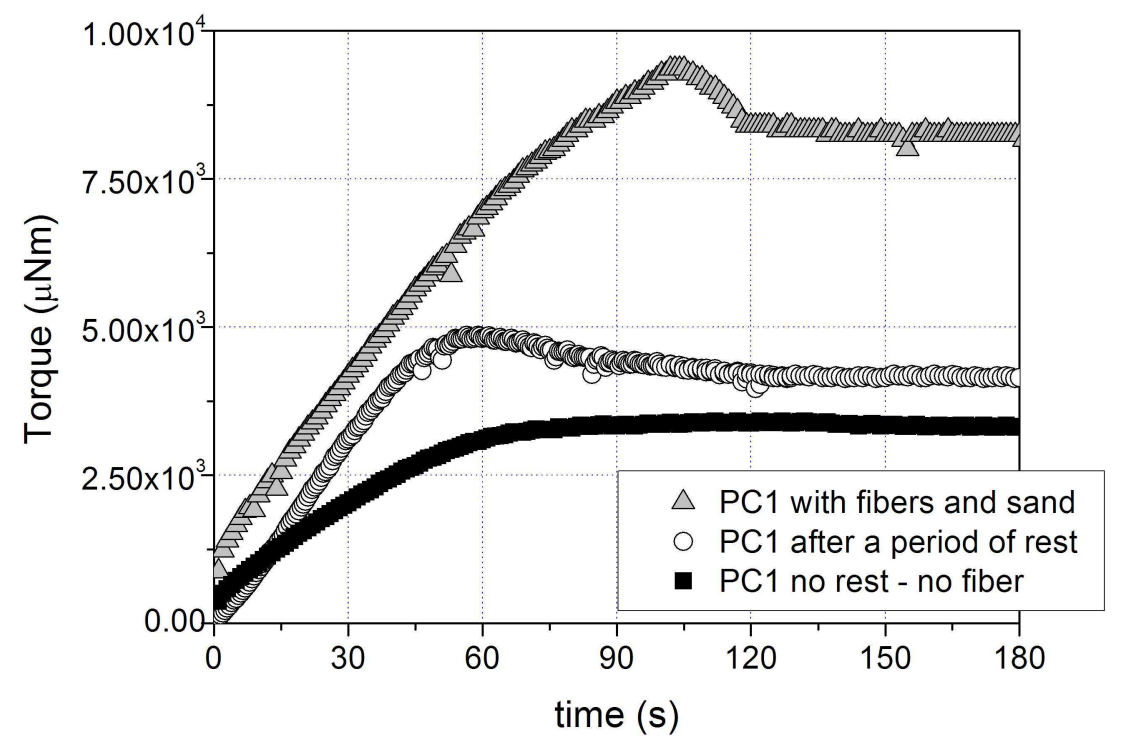

182

Figure 1: Typical torque vs. time curves for different scenarios

184

\section{$185 \quad 3$ Results}

186 Figure 2 shows the evolution of the yield stress vs. time for the mix CP2-0.28S with different

187 amount of fibers. It highlights that the Roussel prediction on the linear evolution of yield

188 stress over resting time accurately describes the material behaviour during the first 40

189 minutes. It means that the $\mathrm{A}_{\text {thix }}$ coefficient is sufficient to model the structural build-up

190 behaviour of the studied materials. The linear increase of yield stress during the first 40

191 minutes is common to all tested mixes. The measured values of $\mathrm{A}_{\text {thix }}$ range between 0.37 and 7

192 Pa.min ${ }^{-1}$. 


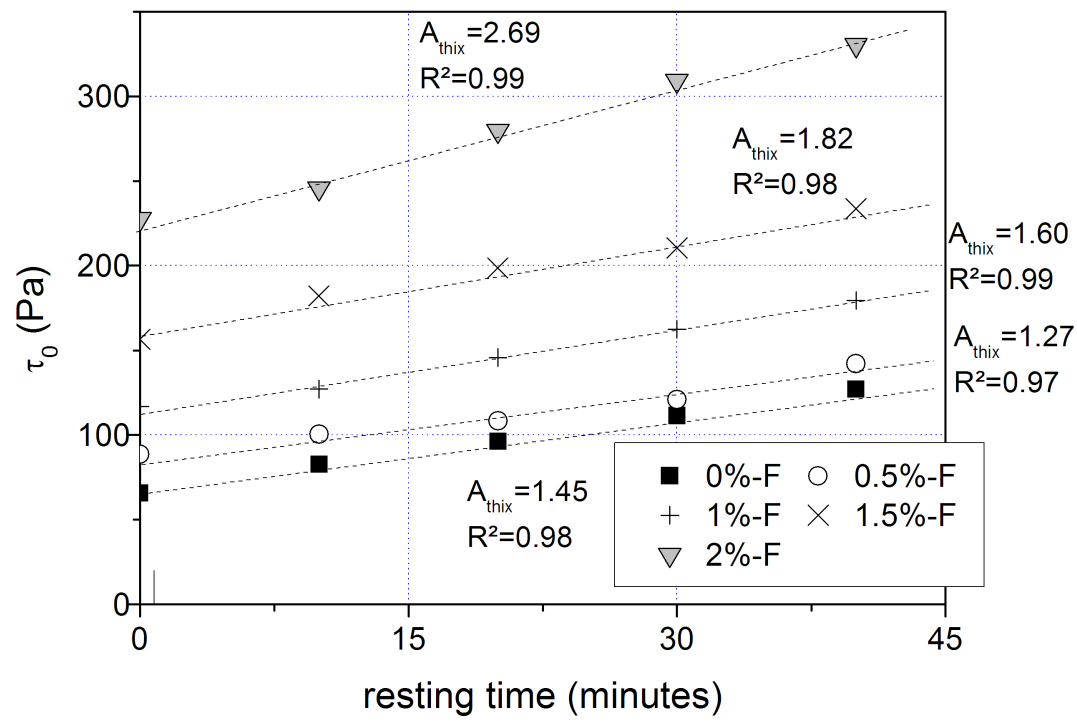

193

Figure 2: Yield stress vs. Resting time for different fiber content (CP1-0.28S)

195

196 According to Martinie et al. (2010), the initial yield stress of rigid fiber reinforced concrete

197 depends on the inclusions relative volume fraction which is defined as the sum of the relative

198 volume fraction of fibers and the relative volume fraction of the granular skeleton:

199

$$
P_{f}=\phi_{f} \cdot \frac{r}{4}+\frac{\phi_{s}}{\phi_{m}}
$$

200 where $\phi_{\mathrm{s}}$ is the volume fraction of sand and $\phi_{\mathrm{m}}$ is the dense packing fraction of the sand 201 (Martinie et al. 2010). The ratio 4/r represents the dense packing of fibers. According to the 202 authors, the real global relative volume fraction of the inclusion mixture is probably 203 underestimated due to wall effects: the decrease of packing fraction of each individual 204 species close to wall is neglected. Also, we assume that each type of inclusions does not 205 modify the packing fraction of the other type of inclusion which is probably wrong. For the 206 used rounded sand, the estimated dense packing fraction is about 0.63.

207 For each mortar, the ratio of its structural build-up rate over the one of the cement paste is 208 plotted on figure 3, versus the relative volume fraction. All experimental values seem to be on 
a same curve. It appears that the structural build-up rate follows the same tendency as the

210 yield stress according to Martinie et al. (Martinie et al. 2010) as it only depends on the

211 inclusions relative volume fraction. As mentioned by those authors, it is possible to combine

212 linearly the effects of both fibers and sand in order to identify the rapid increase in the yield

213 stress of fiber-reinforced cement-based materials around the critical volume fraction at which

214 all these inclusions combine in order to generate a strong direct contact network in the

215 material. Below this critical value, the yield stress of the material is close to the suspending

216 cement paste whereas, above this value, the material yield stress dramatically increases.

217 Finally, the structural build-up rate of a given mortar can be written as a function of the 218 relative volume fraction $\mathrm{P}_{\mathrm{f}}$ and the cement paste structural build-up $\mathrm{A}_{\text {thix }}{ }^{\mathrm{CP}}$ :

$219 A_{\text {thix }}\left(\phi_{s}, \phi_{f}\right)=A_{\text {thix }}^{C P} \cdot g\left(P_{f}\right)$

220 Where $\mathrm{g}\left(\mathrm{P}_{\mathrm{f}}\right)$ is a function depending on $\mathrm{P}_{\mathrm{f}}$. This relationship is similar to the one obtained by

221 Mahaut et al. for mortars (Mahaut et al. 2008b).

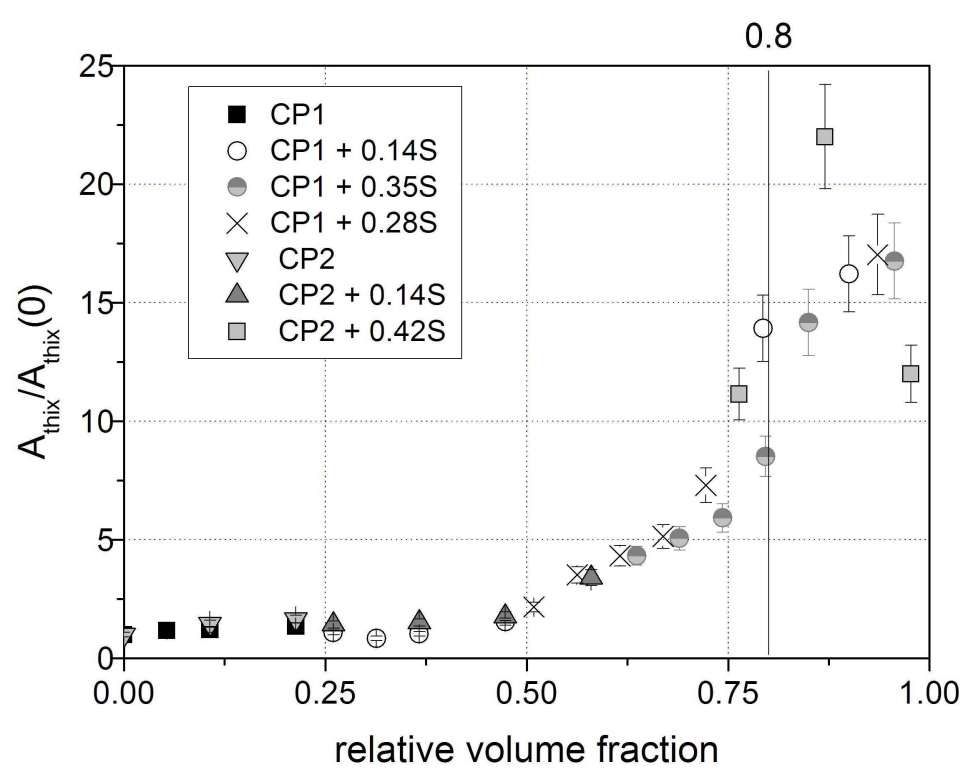

Figure 3: Non-dimensional structural build-up vs. Relative packing

224 Mahaut et al., based on homogenisation work of Chateau et al. (Chateau et al. 2008; Mahaut 225 et al. 2008a; Mahaut et al. 2008b), provide an expression to characterise the evolution of the 
yield stress of a model concrete (with spherical inclusions of the same diameter) as a function of the yield stress of its cement paste $\tau_{0}{ }^{\mathrm{CP}}$ and the volume fraction of it aggregates $\phi_{\mathrm{s}}$ :

$$
\tau_{0}\left(\phi_{s}\right)=\tau_{0}^{C P} \cdot \sqrt{\frac{1-\phi_{s}}{\left(1-\phi_{s} / \phi_{R L P}\right)^{2.5 \phi_{R L P}}}}
$$

229 Where $\phi_{\mathrm{RLP}}$ is the random loose packing fraction of the aggregates.

230 Combining eq. (2) and (6), it is possible to compute $A_{\text {thix }}\left(\phi_{\mathrm{s}}\right)$ for any aggregate fraction from 231 the structural build-up rate of the cement paste $\mathrm{A}_{\text {thix }}{ }^{\mathrm{CP}}$. As a result, $\mathrm{A}_{\text {thix }}$ can be written as 232 follows:

$$
A_{\text {thix }}\left(\phi_{s}\right)=A_{\text {thix }}^{C P} \cdot \sqrt{\frac{1-\phi_{s}}{\left(1-\phi_{s} / \phi_{R L P}\right)^{2.5 \phi_{R L P}}}}
$$

234 This has been experimentally verified by Lecompte et al. (Lecompte et al. 2012) on mortars

235 for aggregate volume fraction ranging from 0 to random loose packing fraction (the range of 236 application of this modelling).

237 It can be interesting to make an analogy between fibers and aggregates for the prediction of 238 the structural build-up and yield stress based on the work of Martinie et al. (Martinie et al. 239 2010). In the work of Mahaut et al., the relative random loose packing fraction writes $\phi_{S} / \phi_{\text {RLP. }}$.

240 According to previous works on granular packing in concrete pastes (Roussel et al. 2010; 241 Yammine et al. 2008), it is possible to write relative random loose packing fraction versus 242 dense packing fraction as $\phi_{\mathrm{RLP}}=0.8 \phi_{\mathrm{m}}$. Then, the relative loose packing fraction for a concrete 243 or mortar without fibers writes:

$244 \frac{\phi_{s}}{\phi_{R L P}}=\frac{\phi_{s}}{0.8 \phi_{m}}$

245 Martinie et al. define an equivalent solid volume fraction $\phi_{\mathrm{s}, \text { eq }}$ for reinforced concretes and 246 mortars by using equation (4) and multiplying it by the dense packing of sand.

$$
\phi_{s, e q}=P f \times \phi_{m}=\phi_{s}+\phi_{m} . \phi_{f} . r / 4
$$


248 Then by analogy, the relative loose packing fraction could become:

$249 \quad \frac{\phi_{s, e q}}{\phi_{R L P}}=\frac{P_{f}}{0.8}$

250 With eq. (9) and (10), it is possible to rewrite the Mahaut et al. relationships (6) and (7) for 251 rigid fiber reinforced cement-based mixes:

$252 \frac{\tau_{0}\left(\phi_{s}, \phi_{f}\right)}{\tau_{0}^{C P}}=\frac{A_{\text {thix }}\left(\phi_{s}, \phi_{f}\right)}{A_{\text {thix }}^{C P}}=\sqrt{\frac{1-\phi_{m} P_{f}}{\left(1-P_{f} / 0.8\right)^{2.5 \cdot P_{f} / 0.8}}}$

253 Comparison between experimental relative yield stress, relative structural build-up rate and 254 predictive modelling for rigid fiber reinforced mortar is shown on figure 4. As predicted by 255 Mahaut et al., the relative yield stress and structural build-up rate follow the same evolution in 256 function of the relative volume fraction $\mathrm{P}_{\mathrm{f}}$ ranging from 0 to 0.8 . One can remark that for $\mathrm{P}_{\mathrm{f}}=$ 2570.8 , the relative volume fraction is equal to the random loose packing fraction, (see equation 258 10). Then, Mahaut et al. modelling is able to describe the evolution of the studied non259 dimensional ratios in the same range of relative volume fraction than for cement-based mixes 260 without fibers. Between $\mathrm{P}_{\mathrm{f}}=0.5$ and $\mathrm{P}_{\mathrm{f}}=0.75$, the modelling slightly underestimates the 261 experimental results, showing the same trend obtained by Lecompte et al. for mortars 262 (Lecompte et al. 2012). An explanation can be that the modelling has been written and 263 validated for monodisperse spheres suspensions. Then, the polydispersity and complex forms 264 of rough sand grains probably induce more energy dissipation that increases the measured 265 shear stress of the tested materials. 


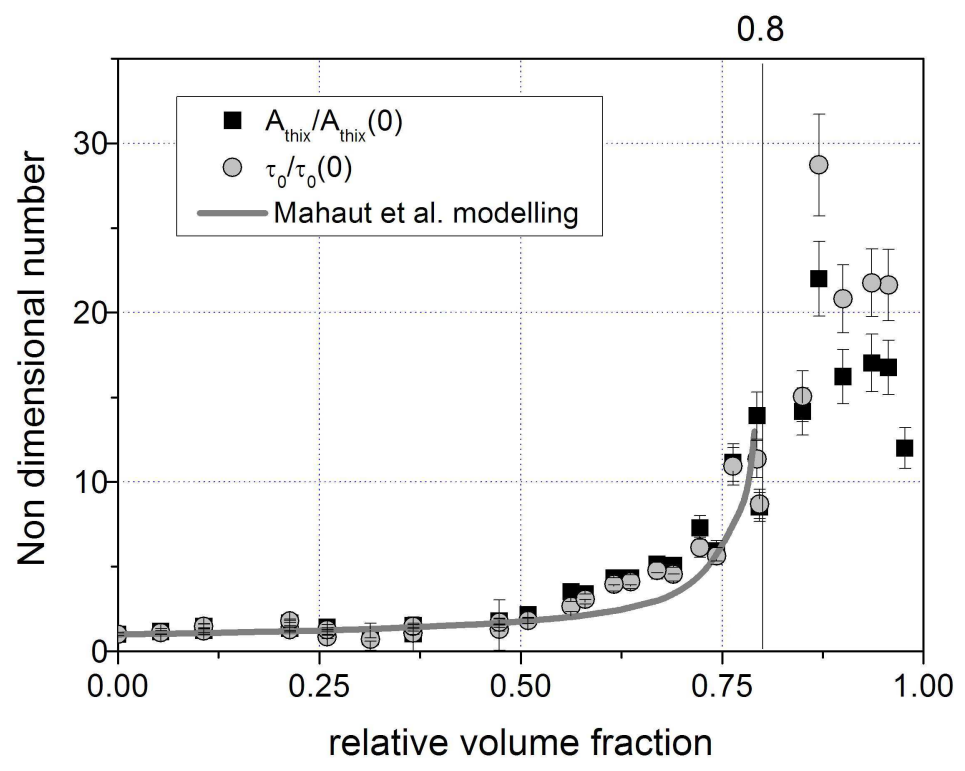

Figure 4: Non dimensional structural build-up and yield stress vs. Relative packing. 268 Comparison with Mahaut et al. predictive modelling (Mahaut et al. 2008a). The plotted relative yield stresses corresponds to measurements with no resting period (dynamic yield stress). The non dimensionnel yield stress for the mix CP2-042S with $2 \%$ fibers is not plotted 271 in this figure $\left(\mathrm{P}_{\mathrm{f}}=0.98 ; \tau_{0} / \tau_{0}(0)=62.3\right)$.

273 Another interesting result is the discrepancy between relative yield stress and relative 274 structural build-up rate observed for relative volume fraction higher than 0.8 where the 275 relative yield stress presents higher values. This results seems similar to the one obtained by 276 Lecompte et al. for mortar (Lecompte et al. 2012). The authors show that high content of inclusions (such as sand and fibers) creates a solid contact network that limits structural build278 up effects.

279 This can be verified by computing a characteristic time $t_{c}$ which corresponds to the time 280 required to double the yield stress value $\left(2 \cdot \tau_{0}{ }^{i}=\tau_{0}{ }^{i}+A_{\text {thix }} \cdot t_{c}\right.$ leads to $\left.t_{c}=\tau_{0}{ }^{i} / A_{\text {thix }}\right)$. Mahaut et 281 al. write that this ratio does not depend on any solid volume fraction but only on the cement 282 paste behaviour. This can be easily verified by dividing eq.(6) by eq.(7). Consequently, for all 
tested mixtures, we should obtain two different values which only depend on the used cement

284 paste $(\mathrm{CP} 1$ or $\mathrm{CP} 2)$. Figure 5 shows the evolution of the characteristic time $\mathrm{t}_{\mathrm{c}}$ versus relative 285 volume fraction. Average values and standard deviations of $t_{c}$ are plotted. Those values are 286 computed separately for each family of mixtures in function of the used cement paste. We 287 note that average value and standard deviation are computed on mixes with a relative volume 288 fraction lesser than 0.8 .

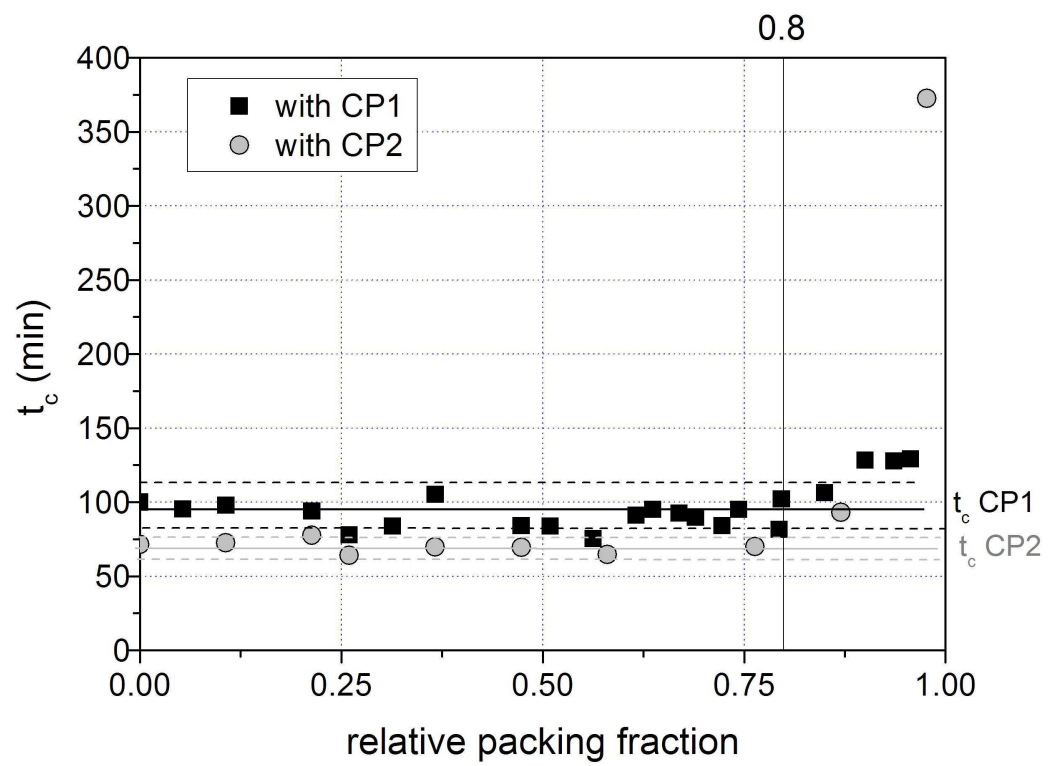

Figure 5: Characteristic structuration time vs. relative packing. Mixes based on cement paste

2911 and 2 (CP1 and CP2). Average values (lines) and standard deviations (dot lines) are plotted 292 in the figure.

293 The figure highlights than the characteristic time $t_{c}$ does not depend on the relative volume 294 fraction when $\mathrm{P}_{\mathrm{f}}<0.8$. For higher value of $\mathrm{P}_{\mathrm{f}}$, the characteristic time value is higher than the one of the cement paste showing that a strong inclusion network slows down structural buildup effect as shown by Lecompte et al. for mortars (Lecompte et al. 2012). 


\section{Conclusions}

The evolution of the structural build-up rate of rigid fiber reinforced concrete has been described in function of mix design parameters such as fibers and aggregate volume fraction.

Based on the study of Martinie et al. (Martinie et al. 2010) about yield stress of rigid fiber reinforced concrete, it has been shown that the structural build-up rate evolution only depends on the total relative volume fraction, $\mathrm{P}_{\mathrm{f}}$.

Then, it has been highlighted that the behaviour of structural build-up depend on the value of $308 \mathrm{P}_{\mathrm{f}}$ :

- Beyond 0.8 (i.e. the random loose packing fraction): the relative structural build-up rate (structural build-up rate of the fiber-reinforced mortar over structural build-up rate of its cement paste) follows the same evolution than the relative yield stress described by Martinie et al. (Martinie et al. 2010). In this case, the structural build-up rate can be predicted by an extension of Mahaut et al. modelling adapted to fibers inclusion (Mahaut et al. 2008a; Mahaut et al. 2008b). The characteristic structuration time $\mathrm{t}_{\mathrm{c}}\left(\mathrm{P}_{\mathrm{f}}\right)$ which defines the time required to double the initial yield stress of the mix does not depend on the relative volume fraction and is equal to the cement paste characteristic

\section{References}


Amziane S, Perrot A, Lecompte T (2008) A novel settling and structural build-up

measurement method Measurement Science and Technology 19 (10):105702
Boulekbache B, Hamrat M, Chemrouk M, Amziane S (2010) Flowability of fibre-reinforced concrete and its effect on the mechanical properties of the material. Construction and Building Materials 24 (9):1664-1671

Boulekbache B, Hamrat M, Chemrouk M, Amziane S (2012) Influence of yield stress and compressive strength on direct shear behaviour of steel fibre-reinforced concrete. Construction and Building Materials 27 (1):6-14

Chateau X, Ovarlez G, Trung KL (2008) Homogenization approach to the behavior of suspensions of noncolloidal particles in yield stress fluids. Journal of Rheology 52 (2):489-506

Colombo M, di Prisco M, Felicetti R (2010) Mechanical properties of steel fibre reinforced concrete exposed at high temperatures. Materials and Structures 43 (4):475-491

di Prisco M, Plizzari G, Vandewalle L (2009) Fibre reinforced concrete: new design perspectives. Materials and Structures 42 (9):1261-1281

Ferrara L, Faifer M, Muhaxheri M, Toscani S (2012a) A magnetic method for non destructive monitoring of fiber dispersion and orientation in steel fiber reinforced cementitious composites. Part 2: Correlation to tensile fracture toughness. Materials and Structures 45 (4):591-598

Ferrara L, Faifer M, Toscani S (2012b) A magnetic method for non destructive monitoring of fiber dispersion and orientation in steel fiber reinforced cementitious compositespart 1: method calibration. Materials and Structures 45 (4):575-589

Ferrara L, Ozyurt N, Prisco M (2011) High mechanical performance of fibre reinforced cementitious composites: the role of casting-flow inducedfibre orientation. Materials and Structures 44 (1):109-128

Ferrara L, Park Y-D, Shah SP (2007) A method for mix-design of fiber-reinforced selfcompacting concrete. Cement and Concrete Research 37 (6):957-971

Kang S-T, Kim J-K (2011) The relation between fiber orientation and tensile behavior in an Ultra High Performance Fiber Reinforced Cementitious Composites (UHPFRCC). Cement and Concrete Research 41 (10):1001-1014

Katzer J, Domski J (2012) Quality and mechanical properties of engineered steel fibres used as reinforcement for concrete. Construction and Building Materials 34 (0):243-248

Kaufmann J, Winnefeld F, Hesselbarth D, Trindler W (2006) Evaluation of the consistency of fiber reinforced cementitious composites. Materials and Structures 39 (6):645-654

Khayat K, Omran A, Naji S, Billberg P, Yahia A (2012) Field-oriented test methods to evaluate structural build-up at rest of flowable mortar and concrete. Materials and Structures:1-18

Kovler K, Roussel N (2011) Properties of fresh and hardened concrete. Cement and Concrete Research 41 (7):775-792

Kuder KG, Ozyurt N, Mu EB, Shah SP (2007) Rheology of fiber-reinforced cementitious materials. Cement and Concrete Research 37 (2):191-199

Lapasin R, Longo V, Rajgelj S (1979) Thixotropic behaviour of cement pastes. Cement and Concrete Research 9 (3):309-318

Laranjeira F, Aguado A, Molins C, Grünewald S, Walraven J, Cavalaro S (2012) Framework to predict the orientation of fibers in FRC: A novel philosophy. Cement and Concrete Research 42 (6):752-768

Laranjeira F, Grünewald S, Walraven J, Blom C, Molins C, Aguado A (2011) Characterization of the orientation profile of steel fiber reinforced concrete. Materials and Structures 44 (6):1093-1111 
Lecompte T, Perrot A, Picandet V, Bellegou H, Amziane S (2012) Cement-based mixes: Shearing properties and pore pressure. Cement and Concrete Research 42 (1):139-147

Mahaut F, Chateau X, Coussot P, Ovarlez G (2008a) Yield stress and elastic modulus of suspensions of noncolloidal particles in yield stress fluids. Journal of Rheology 52 (1):287-313

Mahaut F, Mokeddem S, Chateau X, Roussel N, Ovarlez G (2008b) Effect of coarse particle volume fraction on the yield stress and thixotropy of cementitious materials. Cement and Concrete Research 38 (11):1276-1285

Martinie L, Rossi P, Roussel N (2010) Rheology of fiber reinforced cementitious materials: classification and prediction. Cement and Concrete Research 40 (2):226-234

Martinie L, Roussel N (2011) Simple tools for fiber orientation prediction in industrial practice. Cement and Concrete Research 41 (10):993-1000

Michels J, Waldmann Dl, Maas S, Zürbes A (2012) Steel fibers as only reinforcement for flat slab construction: Experimental investigation and design. Construction and Building Materials 26 (1):145-155

Ovarlez G, Roussel N (2006) A Physical Model for the Prediction of Lateral Stress Exerted by Self-Compacting Concrete on Formwork. Materials and Structures 39 (2):269-279

Perrot A, Amziane S, Ovarlez G, Roussel N (2009) SCC formwork pressure: Influence of steel rebars. Cement and Concrete Research 39 (6):524-528

Pujadas P, Blanco A, de la Fuente A, Aguado A (2012) Cracking behavior of FRC slabs with traditional reinforcement. Materials and Structures 45 (5):707-725

Rokugo K, Kanda T, Yokota H, Sakata N (2009) Applications and recommendations of high performance fiber reinforced cement composites with multiple fine cracking (HPFRCC) in Japan. Materials and Structures 42 (9):1197-1208

Roussel N (2005) Steady and transient flow behaviour of fresh cement pastes. Cement and Concrete Research 35 (9):1656-1664

Roussel N (2006) A thixotropy model for fresh fluid concretes: Theory, validation and applications. Cement and Concrete Research 36 (10):1797-1806

Roussel N (2007) Rheology of fresh concrete: from measurements to predictions of casting processes. Materials and Structures 40 (10):1001-1012

Roussel N, Cussigh F (2008) Distinct-layer casting of SCC: The mechanical consequences of thixotropy. Cement and Concrete Research 38 (5):624-632

Roussel N, Lemaître A, Flatt RJ, Coussot P (2010) Steady state flow of cement suspensions: A micromechanical state of the art. Cement and Concrete Research 40 (1):77-84

Roussel N, Ovarlez G, Garrault S, Brumaud C (2012) The origins of thixotropy of fresh cement pastes. Cement and Concrete Research 42 (1):148-157

Sleiman H, Perrot A, Amziane S (2010) A new look at the measurement of cementitious paste setting by Vicat test. Cement and Concrete Research 40 (5):681-686

Tchamba JC, Amziane S, Ovarlez G, Roussel N (2008) Lateral stress exerted by fresh cement paste on formwork: Laboratory experiments. Cement and Concrete Research 38 (4):459-466

Tokgoz S (2009) Effects of steel fiber addition on the behaviour of biaxially loaded high strength concrete columns. Materials and Structures 42 (8):1125-1138

Torrents J, Blanco A, Pujadas P, Aguado A, Juan-García P, Sánchez-Moragues M (2012) Inductive method for assessing the amount and orientation of steel fibers in concrete. Materials and Structures:1-16

Wallevik JE (2009) Rheological properties of cement paste: Thixotropic behavior and structural breakdown. Cement and Concrete Research 39 (1):14-29

Walraven J (2009) High performance fiber reinforced concrete: progress in knowledge and design codes. Materials and Structures 42 (9):1247-1260 
425 Wang X, Jacobsen S, Lee S, He J, Zhang Z (2010) Effect of silica fume, steel fiber and ITZ on the strength and fracture behavior of mortar. Materials and Structures 43 (1):125139

Wille K, Naaman A, El-Tawil S, Parra-Montesinos G (2012) Ultra-high performance concrete and fiber reinforced concrete: achieving strength and ductility without heat curing. Materials and Structures 45 (3):309-324 rhelogy concrete to self compacting concrete: A transition between frictional and hydrodynamic interactions. Cement and Concrete Research 38 (7):890-896 